\title{
A presença de textos literários em livros didáticos de tendência comunicativa
}

\author{
Frank da Silva Gonçalves \\ CEFET-MG \\ frankup@gmail.com
}

Henrique Alexandrino Pinheiro Alves
École Normale Supérieure de Lyon
henriquealexandrino@yahoo.com.br

\section{Resumo}

Este artigo discute como os textos literários são trabalhados nos livros didáticos de francês língua estrangeira (FLE) elaborados com base na abordagem comunicativa e na perspectiva acional proposta no QECR (2001). Pretendemos situar historicamente o uso de textos literários no ensino de FLE e refletir sobre a presença dos textos literários no livro didático de FLE e sobre as atividades propostas sobre os textos literários. Procuramos esclarecer o uso de textos literários em livros didáticos de FLE. Concluímos que é necessário propor, nos livros didáticos de FLE, atividades que valorizem as especificidades dos textos literários.

Palavras-chave: texto literário; abordagem comunicativa; livro didático.

\begin{abstract}
This article discusses how literary texts are worked in the textbooks for the teaching foreign french drawn from the communicative approach and actionbased approach proposed in QECR (2001). We intend to situate historically the use of literary texts in teaching FLE and reflect on: a) the presence of literary texts in the textbook FLE, b) the proposed activities about literary texts. We want to give a clear idea of using literary texts in textbooks for FLE. We conclude that it is necessary to be proposed, in textbooks FLE, activities giving proper recognition to specificities of literary texts.
\end{abstract}

Keywords: literary text; communicative approach; textbooks. 


\section{Introdução}

A leitura de textos literários no ensino/aprendizagem ${ }^{1}$ de francês língua estrangeira (FLE) nem sempre é valorizada. Na maioria das vezes, isso ocorre devido à ausência de atividades que valorizem as singularidades desses textos e às concepções de leitura literária veiculadas no livro didático de língua estrangeira (LE). Com o objetivo de entender com mais profundidade o uso da literatura, na aprendizagem de línguas, buscaremos, neste artigo, situar historicamente o uso de textos literários no ensino de FLE. Em seguida, com base em uma análise de livros didáticos de LE de tendência comunicativa, apresentamos uma discussão sobre a influência exercida por essa abordagem no trabalho com a literatura e sobre o poder exercido pelo livro didático de LE na leitura desses textos.

A presença da literatura no livro didático de FLE reflete a complexidade pela qual o texto literário é considerado na aprendizagem de LE. Nota-se certa regularidade nas atividades relacionadas à sua utilização e uma ligeira escassez desses textos nos manuais voltados para iniciantes. Na maioria das vezes (PEYTARD, 1982; COSTA, 2002), os textos literários, quando presentes nos livros didáticos, estão envolvidos em atividades de compreensão de leitura e recebem um tratamento pedagógico tradicional de textos não literários. Com vistas à exploração de aspectos estruturais da LE, o texto literário parece atender somente a esse tipo de aproveitamento. Além disso, o tratamento didático conferido aos textos literários, semelhante ao aplicado aos textos não literários, nos leva a supor que o livro didático de LE, na tentativa de expor os aprendizes a gêneros textuais diversificados, não resulta de uma reflexão específica para o uso desses gêneros.

Percebemos, com a leitura de textos sobre a didática do texto literário no ensino/aprendizagem de FLE, que a literatura no livro

\footnotetext{
${ }^{1}$ De acordo com o QECR (CONSEIL, 2001, p. 195), “aprendizagem” é definida como o processo pelo qual é obtida uma capacidade linguística, num ambiente institucional, pelo estudo formal e planejado. Por outro lado, "aquisição" se refere ao conhecimento não orientado e à capacidade de utilização de uma língua não materna, resultantes quer da exposição direta ao texto quer da participação direta em acontecimentos comunicativos.
} 
didático de LE serve de pretexto para a exploração de questões gerais de interpretação que, a princípio, têm por objetivo a fixação de estruturas gramaticais, a produção de frases e o "enriquecimento" de vocabulário. Mesclada a outros gêneros textuais, a literatura parece ocupar, na prática docente, e principalmente no livro didático de FLE, um lugar marginalizado em relação a outros gêneros textuais. Assim, o comum recurso a recortes literários tratados como textos não literários desvaloriza o caráter estético da literatura. Diante disso, há uma ausência de reflexões didáticas quanto ao aproveitamento desses textos no ensino/aprendizagem de FLE.

\section{O livro didático de LE}

O livro didático de LE está geralmente presente na maioria das instituições de ensino de línguas, e por exercer um caráter de autoridade na transmissão de saberes e de conteúdos para professores e alunos (CORACINI, 1999), é considerado um suporte que merece ser questionado para compreendermos como a literatura é por ele introduzida. Argumentamos que, por ocupar um lugar central na sala de aula de línguas, e não raras exceções, "o livro didático corresponde à única fonte de consulta e de leitura dos professore e alunos" (CORACINI, 1999, p.17), ele pode influenciar, por meio do uso que faz da literatura, sua utilização ou não na aprendizagem de línguas. Além disso, questionamos, também se o tipo de aproveitamento feito pelos autores do livro didático da literatura pode, de alguma maneira, servir de modelo para os professores em outras circunstâncias de ensino que não utilizem material didático.

De acordo com Huchinson (1994), a despeito de ser do alvo de críticas negativas ou positivas, o livro didático é um instrumento importante que satisfaz professores e alunos, além disso, ele estabelece uma determinada ordem no "caos" da sala de aula. Para essa autora, os livros didáticos sobrevivem e exercem um papel fundamental no ensino de LE, "principalmente porque são os meios mais convenientes de oferecer a estrutura que o sistema de ensino-aprendizagem, particularmente o sistema de mudança requer" (1994, p.317). Dessa forma, o livro didático assegura às instituições de ensino a aplicação de determinada orientação metodológica e possibilita uma uniformização 
dos conteúdos a serem trabalhados em sala de aula. Um dos grandes problemas dessa visão de livro didático reside no fato de que, ao pensar dessa forma e trazer o "prato feito" da estrutura de um curso, ele pode "alienar" alunos e, principalmente professores quanto a uma forma de ensino/aprendizagem de LE. Mais grave ainda seria o fato de que muitos professores sem formação continuada não saberiam manipular com autonomia esse "prato feito" (ALMEIDA-FILHO, 2007).

Reconhecer a autoridade que o livro tem é, por um lado, admitir as inúmeras consequências disso para o ensino de línguas. Assim, ao mesmo tempo em que os professores utilizam o livro didático de LE para ensinar determinado conteúdo, participam e legitimam, direta ou indiretamente, as propostas pedagógicas possibilitadas pelo livro didático com os aprendizes. Dessa interação advém, portanto, adotar a filosofia de ensino/aprendizagem, a visão de língua e de literatura contidas no livro adotado. Isso não significa, por outro lado, negar a existência de um desenvolvimento satisfatório que possa resultar dessa interação.

De acordo com Kitao (1997), o aluno aprende da forma que livro didático ensina. Assim, ele determina a maneira como os alunos aprenderão e o que irão aprender. Composto de vários elementos: livro do professor, caderno de exercícios, DVD, etc., o livro didático de LE cerca todas as possibilidades de autonomia dos envolvidos e conserva sua posição institucionalizada no ensino/aprendizagem de LE. Segundo Riquois,

O manual é então uma obra única escolhida pela instituição escolar e que deve ser seguido página por página e cujas atividades devem ser realizadas com os aprendizes. O ensino é guiado, e também compelido, o que pode trazer segurança para o professor, porém não lhe concedendo nenhuma liberdade, principalmente para se adaptar ao seu público $(2010 \mathrm{a}, \mathrm{p.130})^{2}$.

${ }^{2}$ Le manuel est alors un ouvrage unique choisi par l'institution scolaire qui doit être suivi page après page et dont toutes les activités doivent être réalisées avec les apprenants. L'enseignement est guidé, voire contraint, ce qui peut être sécurisant pour l'enseignant, mais ne lui laisse aucune liberté, notamment pour s'adapter à son public. 
Nessa perspectiva, é preciso questionar o valor que o livro didático tem, sem o objetivo de eliminá-lo, mas com a finalidade de melhorá-lo cada vez mais. Sabemos que não existe um livro didático perfeito (PRABHU, 1990) e por isso devemos compreendê-lo para torná-lo mais eficiente. Segundo Batista (2000), existe um forte discurso pedagógico que responsabiliza o livro didático pela dissociação entre aqueles que concebem materiais de ensino e aqueles que os colocam em prática na sala de aula. Para ele essa distinção seria o principal fator de desqualificação e de distorções na formação dos docentes. Concordamos com Prabhu (1990) quando ele destaca que o professor deve aprender a manipular o livro didático de forma a maximizar as propostas pedagógicas ali presentes em proveito da aprendizagem dos aprendizes. E como não há um manual de línguas universal que se adeque às especificidades de cada aprendiz, ressaltamos, também, a adoção de uma postura eclética quanto à utilização de livros didáticos, sugerida por esse autor.

A questão da literatura, no livro didático de língua estrangeira, defronta-se com outro dilema, a teoria de língua adotada por determinada metodologia de ensino LE. De acordo com Richards e Rodgers (2003), no ensino/aprendizagem de LE podem ser adotados três pontos de vista:

a) o estrutural em que se considera a língua um sistema de elementos relacionados estruturalmente para codificar $o$ significado;

b) o funcional em que se considera a língua um veículo de expressão de um significado funcional e

c) o interativo em que se considera a língua um veículo para o desenvolvimento de relações pessoais e transações sociais entre os indivíduos.

Tais orientações, por muitas vezes, se excluem ao invés de se complementarem. E a adoção de uma dessas dimensões irá reger o ensino/aprendizagem da língua e com isso, a estrutura do livro didático.

Dessa forma, acreditamos que a teoria de língua adotada pelos autores de materiais de ensino determinará a maneira como a literatura será aproveitada no manual de línguas.

É importante salientar que o desenvolvimento de um livro didático de LE depende de fatores que estão ligados à metodologia de 
ensino de línguas ao qual está vinculado. Assim, o livro didático de FLE, tal qual temos hoje, passou por inúmeras adaptações resultantes das diferentes correntes metodológicas já aplicadas na didática de ensino de LE.

\subsection{O texto literário no livro didático de FLE}

No livro didático de FLE, percebemos que a presença da literatura variou em função da importância creditada à Literatura ou do caráter autêntico conferido ao texto literário. Naturel (1995) indica três períodos importantes pelos quais passou a literatura nos manuais de FLE: grandeza, decadência e renovação. O período de grandeza da literatura corresponde à vigência da metodologia tradicional ou gramático-tradução, do final do século XVI à década de 1950 do século XX, quando o texto literário possuía um lugar consolidado no ensino de FLE. Um dos volumes da coleção de livros didáticos, em geral o último, estava totalmente reservado ao texto literário. Resguardado o seu valor estético, ela era concebida como o aperfeiçoamento da aprendizagem da língua francesa. Como destacam Cuq e Gruca (2005, p.415), "paradoxalmente, tudo se passava como se o contato com os textos de grandes autores só pudesse ocorrer antes de um longo contato com textos fabricados para fins linguísticos e pedagógicos"3. É o caso, por exemplo, dos manuais: Cours de langue et de civilisation française (1953), la France en direct (1969) e Le Français et la vie (1971).

Além disso, essa visão de leitura literária em FLE denota a influência de concepções pedagógicas que vigoram até hoje e que giram em torno da sacralização ou banalização da literatura. No primeiro caso, os textos literários são introduzidos desde as primeiras lições dos livros didáticos; no segundo esses textos, ainda que figurem nos livros de LE, são inseridos sem que suas singularidades sejam observadas. Trata-se de um texto autêntico a mais para se trabalhar a compreensão de leitura. Assim, podemos afirmar que essa oscilação de importância da literatura no livro didático de FLE sinaliza uma

\footnotetext{
3 Paradoxalement, tout se passait donc comme si la fréquentation des textes des grands auteurs ne pouvait se mériter qu'après une longue fréquentation des textes fabriqués à des fins linguistiques et pédagogiques.
} 
indefinição quanto a real função desses textos no ensino/aprendizagem de línguas.

Ao final de 1970 e início de 1980, os textos literários passam a ter pouca representatividade nos manuais de língua em relação ao status que possuíam em 1950. De acordo com Naturel (1995, p.19) "a partir dos anos 80, os textos literários ficam cada vez mais raros". Aparecendo "no volume III dos manuais de francês língua estrangeira, porém sua presença tinha como função ilustrar um tema de estudo, fenômeno de sociedade, etc". É nesse período que a literatura começa a dividir espaço com outros textos autênticos no livro didático de FLE. Ao confundir-se com outros textos, começava a perder seu caráter estético,pois sua literariedade ${ }^{4}$ não era considerada. No final da década de 1980 e início de 1990, os textos literários voltam a figurar no livro didático influenciado pelo surgimento da abordagem comunicativa.

Naturel (1995) afirma também que, direta ou indiretamente, a abordagem do texto literário nos livros de FLE estava fundamentada em algum pressuposto teórico em voga na época. Assim, os manuais que privilegiavam o autor eram influenciados pela crítica biográfica; as atividades voltadas para o texto confirmavam um vínculo com o estruturalismo. Para os manuais orientados pela estética da recepção, percebia-se, nas atividades propostas, uma valorização da participação do leitor, de modo a considerar o seu ponto de vista e seus comentários sobre os textos.

Análises de livros didáticos de FLE (COSTA, 2002; RIQUOIS, 2010; CUQ e GRUCA, 2005), após a década de 1990, mostram que a reinserção da literatura na aprendizagem de línguas ocorre em forma de fragmentos literários ao fim de cada unidade do livro didático. Entretanto, a prática de leitura e das atividades propostas não possibilitam a troca de experiências, as discussões e as interpretações dos aprendizes. Assim, embora a reintrodução dos textos literários no ensino de línguas tenha fortalecido a importância da presença do texto literário, influenciada por pesquisas que valorizavam sua utilização em aulas de FLE (GOLDENSTEIN, 1990, NATUREL,

4 Conceito utilizado por Naturel (1990), segundo Oulipo: "todo texto literário é literário por possuir uma quantidade indefinida de significações potenciais". (OULIPO. La littérature potentielle: créations, re-créations, récréations. Paris: Gallimard, 1973, p. 31 apud NATUREL, 1995). 
1995, CICUREL, 1991, PEYTARD, 1982; PAPO e BOURGAIN, 1989), a literatura parece ainda ser empregada sem que suas especificidades sejam valorizadas. Cuq e Gruca (2005) salientam o fato de que ao reintegrar a literatura aos materiais de aprendizagem de línguas, a abordagem comunicativa parece não suscitar um discurso específico para o domínio da literatura. E esta aparente ausência de reflexão didática, sobre o uso da literatura na abordagem comunicativa, talvez seja a razão para a grande variação de propostas pedagógicas sobre os textos literários verificada nos manuais de FLE de orientação comunicativa. Com o intuito de perceber como se deu o retorno dos textos literários na abordagem comunicativa, apresentamos, em seguida, uma análise de livros didáticos relativos a esse contexto. Nessa análise verificamos como esses textos são trabalhados em vista das habilidades mais exploradas e da dimensão cultural. Além disso, procuramos perceber a inexistência e/ou persistência na restrição desses textos para os níveis iniciantes.

\section{O texto literário na Abordagem Comunicativa}

Com intuito de compreender mais detalhadamente a questão do uso do texto literário, hoje em dia, começamos com uma breve contextualização dessa abordagem, seguida por uma elucidação do conceito de "competência comunicativa", que fundamenta o desenvolvimento de um modelo didático para o ensino de FLE. Posteriormente, propomos uma análise de alguns livros didáticos de FLE que reivindicam a abordagem comunicativa. Tentamos extrair, dessa análise, as principais características do tratamento dado ao texto literário. Focamos nossa atenção nos tipos de atividades que são propostas pelos diferentes autores dos livros didáticos para trabalhar a literatura.

A abordagem comunicativa desenvolveu-se na França no final da década de 1970 em continuidade ao método audiovisual. De acordo com Cuq e Gruca (2005, p. 264), a abordagem comunicativa nasceu de um cruzamento de fatores políticos e teóricos. O surgimento dessa abordagem estava associado a uma necessidade de integração dos diferentes países da Comunidade Econômica Europeia. O objetivo era favorecer a integração dos países europeus por meio de um 
aprendizado de LE. Em relação ao segundo fator, Berard (1991, p.17) afirma que

(...) a abordagem comunicativa tem a particularidade de diversificar os empréstimos aos quais ela recorre. Essa diversificação se faz em um momento em que a linguística não é mais dominada por uma grande corrente e onde se desenvolve um conjunto de disciplinas que fornecem objetos específicos de trabalho: sociolinguística, psicolinguística, etnografia da comunicação, análise do discurso, pragmática $(\ldots)^{5}$

A autora mostra que o surgimento da abordagem comunicativa está intrinsecamente ligado ao desenvolvimento de novas teorias linguísticas e, em particular, à consolidação de uma disciplina que se viu enriquecida com novos campos teóricos. Destacamos, ainda, outro fator que contribuiu para o desenvolvimento dessa abordagem: o surgimento de um novo público, adulto, composto principalmente por imigrantes com necessidades linguísticas específicas. Ancorada nessa noção de "necessidade", a abordagem comunicativa orienta a progressão da aprendizagem, que passa, assim, a ser considerada um processo ativo regido pelo próprio indivíduo. Do ponto de vista cultural, a abordagem comunicativa inova ao aproximar o ensino do contexto de aprendizagem do aluno por meio dos chamados textos "autênticos". Esses textos se destinam a promover a aquisição de saberes linguísticos e especialmente os de fundo cultural. Em contraste com textos fabricados devido às restrições linguísticas, os textos considerados autênticos testemunham o uso real da língua em uma dada situação de comunicação. Em outras palavras, são discursos produzidos em meio endolingue para os leitores francófonos.

Essa abordagem fez da comunicação sua peça-chave e destacou o propósito da educação, aprender a se comunicar em uma LE

5 (...) l'approche communicative a comme particularité de diversifier les emprunts théoriques auxquels elle a recours. Cette diversification se fait à un moment où la linguistique n'est plus dominée par un grand courant et où se développe un ensemble de disciplines qui donnent des objets de travail spécifiques : sociolinguistique, psycholinguistique, ethnographie de la communication, analyse $d u$ discours, pragmatique (...) 
de forma eficaz. A língua é vista, agora, como um instrumento de comunicação e interação social. Aprender uma língua não se resume mais a uma assimilação de hábitos e reflexos. Portanto, o conhecimento do sistema linguístico não é mais a única prerrogativa necessária para a aquisição das competências de comunicação. Mais do que isso, é preciso saber se servir desse sistema em função do contexto social em que a língua é utilizada (BACHMAN; LINDENFELD; SIMONIN, 1981 apud BERARD, 1991).

Referimos o conceito desenvolvido por Hymes (1972) em que a competência comunicativa considera um conjunto de regras linguísticas, bem como as devidas regras de utilização da língua. Canale e Swain (1980) aprofundam essa noção, subdividindo-a em três outras competências: a competência gramatical; a competência sociolinguística; e, por fim, uma competência estratégica, que estaria ligada às estratégias que o falante utiliza para evitar as falhas na comunicação. Ainda acerca dessa competência, é imprescindível ressaltar os estudos de Moirand (1982), que colocam em evidência as dimensões discursiva, referencial e sociocultural, paralelamente, à aquisição de componentes linguísticos (conhecimento das regras e das estruturas gramaticais). Desse modo, percebemos que o desenvolvimento do conceito de competência de comunicação e, de maneira subjacente, o conceito de língua veiculado pela abordagem comunicativa, tende a se tornar mais complexo.

Quanto à aplicação das teorias linguísticas que fundamentam a abordagem comunicativa, resta ainda muito a dizer. Limitamo-nos, neste estudo, ao fato de que a apropriação e a utilização das contribuições teóricas, advindas de diferentes ramos da Linguística para consolidar uma "metodologia" pertinente, não nos parece algo tão simples. Concordamos com Berard (1991), ao concluir que a imprecisão metodológica existente na abordagem comunicativa pode ser explicada pela heterogeneidade das contribuições teóricas às quais essa abordagem recorre. Isso explicaria algumas das críticas feitas à abordagem comunicativa, sobretudo àquelas que se referem ao grau de artificialidade da língua ensinada. Desse modo, supomos que o trabalho com textos literários nessa abordagem será influenciado pela tentativa de aproximar o aprendiz a um uso "real linguístico", calcado na aprendizagem de uma língua artificial, que não considera a dimensão social tão importante na leitura dos textos literários. Essa 
reflexão nos permite também compreender maneira contraditória do retorno do texto literário na abordagem comunicativa. Considerado, na maioria das vezes, um texto autêntico - instrumento para familiarizar o aprendiz com a língua e com a cultura estudadas - torna-se muitas vezes "um intruso performante" (ELENA, 2005), pretexto para o puro ensino de componentes linguísticos.

\section{Análise de livros didáticos de FLE}

Para fornecer uma visão ampla do uso pedagógico do texto literário na abordagem comunicativa, efetuamos uma análise de quatro livros didáticos de FLE destinados a um público de adultos e jovens e editados na França entre 1982 e 2007. Esse período corresponde à chegada da abordagem comunicativa no campo da didática de LE e à sua transição para uma perspectiva acional. Os quatro manuais foram publicados por três grandes editoras de livros didáticos de FLE na França: Didier, Clé International e Hachette. Nosso corpus é composto dos seguintes livros: Archipel (volumes 1, 2 e 3), um dos primeiros livros da abordagem comunicativa propriamente dita, Café Crème (volumes 1, 2, 3 e 4), Champion (volumes 1 e 2) e, finalmente, o livro Tout va bien! (volumes 1, 2, 3 e 4), que marca com clareza a transição para a perspectiva acional.

A análise dos livros didáticos foi orientada por três eixos centrais: os textos literários presentes nos livros, o tipo de exploração pedagógica desses textos e o trabalho cultural efetuado com base neles. Apresentamos inicialmente uma síntese dos objetivos de cada livro, seguida de uma descrição e da discussão da exploração pedagógica proposta para os textos literários.

O livro Archipel, editado entre 1982 e 1987, início da abordagem comunicativa, confere um lugar importante à compreensão escrita e, por conseguinte, ao texto literário, presente desde o nível 1. $\mathrm{O}$ número de textos aumenta na medida em que o aluno progride. Esse livro utiliza também textos fabricados para fins didáticos que, pouco a pouco, cedem lugar aos textos autênticos. O texto literário suscita, nesse livro, uma produção escrita, entretanto esse trabalho de reinvestimento restringe-se à imitação de um modelo pré-estabelecido fornecido pelo texto literário. Trata-se, assim, de encontrar "uma 
fórmula", geralmente sintática, que rege o texto e de reproduzi-la. Contudo, podemos inferir que esse livro atesta a importância dos textos autênticos - que compreendem os textos literários - e ressalta, também, o retorno da literatura, após o período de utilização da metodologia direta que limitava o contato com esses textos aos níveis avançados.

Os livros Café Crème e Champion, analisados em seguida, fornecem uma ideia de um período de "consolidação" da abordagem comunicativa. Durante esse período, verificamos a valorização de um ensino que prioriza a aquisição das competências de comunicação, o objetivo central do ensino de LE é formar "verdadeiros locutores" em LE. O manual Café Crème, editado entre 1997 e 1999, atribui ao texto literário um lugar secundário, uma vez que ele se concentra no desenvolvimento das competências de comunicação oral. O texto literário está ausente no nível 1, uma das razões que poderiam justificar essa ausência seria o fato de que o texto literário é, muitas vezes, considerado um texto autêntico de difícil compreensão para os alunos iniciantes. Os textos literários são introduzidos a partir do nível 2, contudo, observamos que esses textos são destinados a ilustrar uma situação de comunicação. Eles têm geralmente uma estrutura dialogal, por isso o interesse desse livro pelo gênero dramático.

Com relação ao livro Champion, editado no final dos anos 1990 e reeditado entre 2001 e 2002, percebemos que seu objetivo é a aquisição de saberes comunicativos e linguísticos. ${ }^{4}$ A aquisição de uma competência de comunicação em LE orientou, assim, a escolha dos diferentes documentos autênticos que, geralmente, são gêneros textuais de circulação comum em diferentes línguas. Embora o texto literário seja tratado como texto autêntico pela abordagem comunicativa, ele está totalmente ausente nesse livro.

Finalmente, o último manual analisado, que testemunha um período que poderíamos qualificar de "pré-acional", é a coleção Tout va bien! que começou a ser utilizada nos anos 2000, a qual apresenta textos desde o primeiro nível. Os diferentes textos literários são propostos em consideração ao objetivo central desse manual: adquirir uma competência de comunicação oral e escrita. Essa coleção tenta,

\footnotetext{
${ }^{4} \mathrm{Na}$ introdução, a autora afirma que esse livro permite ao aluno comunicar em situações quotidianas, oralmente e por escrito.
} 
assim, reunir a aquisição de uma competência comunicativa e a autonomia do aluno que, agora, tem uma aprendizagem orientada pela perspectiva acional (QECR, 2001). Segundo essa perspectiva o aluno é convidado a se tornar um "ator social" capaz de realizar inúmeras tarefas em LE.

Após essa breve contextualização, vamos nos concentrar em uma análise profunda sobre a inserção dos textos literários nos livros didáticos selecionados, sobre o tipo de exploração pedagógica feita e, finalmente sobre as relações estabelecidas entre língua e cultura no trabalho com a literatura.

Com relação à presença de textos literários nos livros didáticos analisados, percebemos que essa é ainda muito instável. A figura 1 e a tabela 1 mostram o número de textos literários por nível nos livros didáticos analisados.

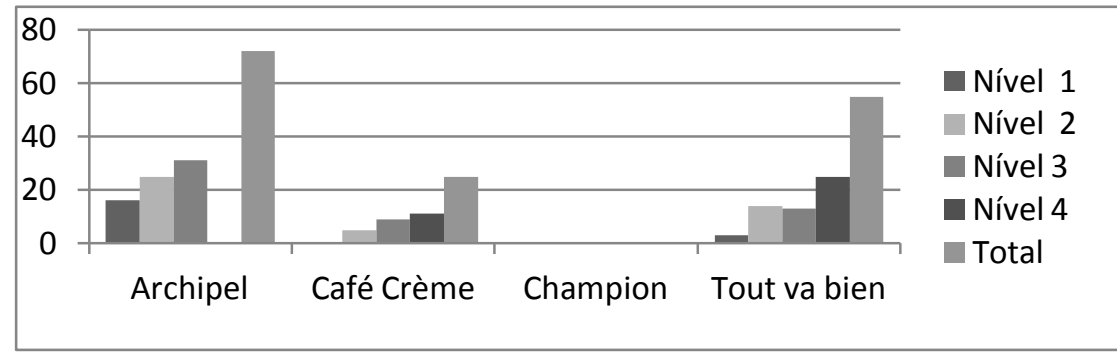

Figura 1. Frequência de textos literários nas coleções de LDs por nível

Tabela 1. Frequência de textos literários por $L D$

\begin{tabular}{|c|c|c|c|c|c|}
\hline \multirow[t]{2}{*}{ LD } & \multicolumn{4}{|c|}{ Nível } & \multirow[t]{2}{*}{ Total } \\
\hline & 1 & 2 & 3 & 4 & \\
\hline Archipel & 16 & 25 & 31 & 0 & 72 \\
\hline Café Crème & 0 & 5 & 9 & 11 & 25 \\
\hline Champion & 0 & 0 & 0 & 0 & 0 \\
\hline Tout va bien! & 3 & 14 & 13 & 25 & 55 \\
\hline
\end{tabular}

Conforme percebemos, a presença do texto literário é muito instável na abordagem comunicativa. De maneira geral, o texto literário está raramente presente e às vezes ausente nos níveis 
iniciantes (1 e 2) - com exceção do livro Archipel - e massivamente presente nos níveis intermediário e avançado (3 e 4). Isso nos faz deduzir que, nessa abordagem, o texto literário é considerado um texto de difícil acesso para níveis linguisticamente fracos. No livro Archipel, foram utilizados textos fabricados, nos níveis iniciais, para introduzir o texto literário dentro de uma progressão gramatical.

Constatamos que a presença dos textos literários no corpus se faz pela utilização de trechos, fragmentos de textos retirados de seu contexto de produção. Poucas informações são dadas sobre o próprio texto, sobre os autores e sobre o contexto sócio-histórico de suas publicações. Nenhum elemento é fornecido para facilitar compreensão dos textos literários. $\mathrm{O}$ segundo aspecto a ser observado refere-se às inúmeras citações de escritores, referências a autores e a obras literárias com a finalidade de ilustrar ou introduzir uma temática dentro de uma lição. Diante dessa postura, deduzimos que o universo literário encontra-se disperso e fragmentado nos diferentes livros didáticos e essa falta de referência precisa prejudica, muitas vezes, a compreensão do texto literário. Acreditamos que o aprendiz precisa reconhecer facilmente o texto literário para, em seguida, mobilizar os conhecimentos e as competências de leitura específicas numa leitura literária.

$\mathrm{Na}$ análise do corpus deste trabalho distinguimos as três fases da abordagem comunicativa concernentes ao texto literário: primeiramente, temos uma fase de "reintrodução" do texto literário, o que poderia explicar o grande número de textos presentes no livro Archipel. Em seguida, uma fase de consolidação dessa abordagem, em que o centro de interesses é a aquisição de uma competência de comunicação. A oralidade ocupa, assim, um lugar importante e o escrito só é valorizado como documento de interação ou fonte de informação para as práticas linguageiras quotidianas. O que explicaria a baixa presença de textos literários em todos os níveis de aprendizagem. Finalmente, uma terceira fase em que assistimos a um retorno considerável do texto literário em todos os níveis, uma fase que poderíamos qualificar de pré-acional.

Com relação aos gêneros literários presentes nos livros analisados, percebemos como gêneros mais frequentes: a poesia, o romance, o conto, a novela, o gênero dramático, a fábula e a chamada literatura de ideias (discurso e ensaios). Esses diferentes gêneros são 
selecionados, nos livros didáticos, de acordo com nível de aprendizagem, ou seja, a poesia, a prosa curta e as peças de teatro são fortemente presentes nos níveis 1 e 2 . Por outro lado, os romances e a literatura de ideia destinam-se aos níveis intermediário e avançado. Essa distribuição de gêneros nos livros analisados não é nem rígida, nem hierárquica; ela obedece frequentemente a uma progressão ligada à aquisição de competências comunicativas e, sobretudo, aos conhecimentos gramaticais. Contudo, não está excluída a possibilidade de os livros utilizarem trechos de romance no nível iniciante desde que esses tenham uma estrutura gramatical simples.

Ainda a respeito dos gêneros literários, atribuímos uma atenção aos gêneros paraliterários que ocupam um importante lugar nos livros de FLE. As narrativas policiais e de ficção científica, romances de aventura e pastiches estão muito presentes e dão, aos alunos, uma visão mais acessível da literatura, uma vez que elas oferecem cenários de leitura conhecidos e consequentemente de fácil produção de sentido.

Outro aspecto interessante que merece nossa reflexão concerne à gama de escritores representados nos quatro livros didáticos analisados. Os autores dos livros didáticos não se restringiram apenas ao cânone literário do hexágono. Vimos emergir, nos livros didáticos, escritores francófonos, escritores estrangeiros que escolheram o francês como língua de expressão e, às vezes, escritores estrangeiros traduzidos em francês. Os livros publicados recentemente como Tout va bien! têm uma preferência por escritores contemporâneos que fazem parte da vida literária atual. Esses autores são tratados, de certa maneira, como personagens da vida pública que se exprimem por intermédio da escrita. A nosso ver, constitui-se de uma estratégia para aproximar o aluno do texto literário que, na maioria das vezes, é sacralizado pelo seu status de "obra de arte".

A reflexão acerca do lugar ocupado pelo texto literário nos manuais que analisamos leva-nos a pensar sobre as propostas pedagógicas elaboradas pelos autores desses suportes. Para isso, focaremos nossa atenção nas atividades propostas e, igualmente, nos objetivos de ensino subjacentes a essas atividades. A reflexão que pretendemos tecer vai ao encontro do pensamento de Riquois (2010, p.250) que afirma que "a exploração pedagógica do texto literário em sala de aula de FLE indaga efetivamente a questão da adequação entre 
aprender uma língua e ler um texto literário”. Nesse caso, qual seria o objetivo principal da leitura literária: compreender o funcionamento da língua ou desenvolver a competência de leitura em LE? A fim de responder a essa questão, nossa atenção voltou-se para as estratégias de utilização didática da literatura nos quatro manuais analisados. Ao longo da análise evidenciamos, nos textos literários presentes no corpus, diferentes tipos de atividades, a saber: a) atividades de compreensão escrita e oral; b) atividades de expressão escrita e oral; c) atividades gramaticais; d) atividades textuais (tipo e gênero) e atividades culturais (aspectos da civilização francesa, usos e costumes).

Essas diferentes atividades são propostas pelos autores dos livros didáticos em função dos objetivos pedagógicos fixados para cada lição do manual. Além de aprender uma "língua-cultura", outra função é atribuída ao texto literário pelos autores de livros didáticos; trata-se de uma função de cunho puramente ilustrativo. Nesse caso, nenhuma atividade é prevista de forma explícita no manual do aluno. Isso nos leva a inferir que o texto literário teria a função de ilustrar uma temática ou um conteúdo gramatical focalizado na lição. Ao funcionar como um elemento figurativo, passa a integrar de maneira mais ou menos harmoniosa o layout da lição.

Observamos que as atividades propostas no corpus são majoritariamente escritas, guiadas por questões que solicitam do aprendiz o mapeamento e/ou a classificação de informações. Entretanto, a competência de leitura do aprendiz estrangeiro relacionada com a enciclopédia do leitor ${ }^{5}$ é raramente mobilizada. Esse trabalho de compreensão, sobretudo nos níveis intermediário e avançado, aproxima-se do trabalho interpretativo comumente efetuado em língua materna. Algumas vezes, a atividade de compreensão não é guiada, por conseguinte, nenhum trabalho é previsto. É o que alguns livros didáticos chamam de "leitura de prazer".

A respeito do papel que os livros didáticos da abordagem comunicativa atribuem à leitura literária, percebemos que os exercícios propostos nos livros, para textos literários e não literários, são

\footnotetext{
${ }^{5}$ Emprestamos, aqui, o conceito desenvolvido por Umberto Eco na sua obra "Lector in fabula". Em outras palavras, o leitor mobiliza os conhecimentos do mundo dos quais ele dispõe para ligá-los às informações lidas no texto.
} 
orientados por uma visão funcionalista. Assim, o principal objetivo do ensino de leitura, nos manuais analisados, seria ampliar os conhecimentos dos alunos no domínio da leitura e da escrita, a fim de prepará-los para a interação escrita da vida quotidiana. A leitura seria, assim, associada a um caráter prático, que valorizaria somente alguns gêneros (textos jornalísticos, receitas, manuais de instruções, folders etc) a despeito de uma leitura literária que seria fundamentalmente calcada na noção de prazer.

Em relação às atividades de expressão escrita, os exercícios propostos pelos livros didáticos se assemelham. Geralmente, os alunos são convidados a produzir textos com base em um modelo fornecido, o do texto literário lido. Os alunos devem imitar a estrutura sintática do texto em questão. Os exercícios de escrita criativa são raramente propostos, e o comentário de texto torna-se uma das ferramentas imprescindíveis à produção escrita nos níveis intermediário e avançado.

As atividades que pressupõem um trabalho oral são, com efeito, raras uma vez que a oralização de textos literários é menos frequente. Os livros didáticos utilizam leituras feitas por atores com base nas quais eles propõem uma atividade de compreensão oral guiada por questões. Essa compreensão tem por objetivo reconhecer a situação de comunicação e extrair informações precisas do texto. Nessa direção, as atividades de expressão oral não são orientadas por um trabalho efetivo. Essas atividades são inseridas em um contexto de discussão informal em torno do texto lido e, consequentemente, o texto literário torna-se um pretexto para iniciar uma conversa. Observamos também que os livros didáticos propunham a criação de diálogos espontâneos a serem encenados com base em textos literários. Todavia, a relação entre o texto e a produção visada nos parece extremamente vaga e distancia-se, muitas vezes, das possíveis leituras que o texto lido permitiria.

Os livros didáticos analisados propõem, também, atividades com vista à aquisição de conhecimentos linguísticos. Dessa forma, o texto literário é utilizado para ensinar regras de gramática, de pronúncia e léxico aos aprendizes. Essas atividades evidenciam uma separação entre forma e conteúdo, isto é, o importante nesse tipo de atividade não são as ideias e o sentido que o leitor pode extrair do texto, mas a estrutura, a ossatura linguística que combina e organiza as 
palavras. São exercícios em que o aprendiz deve completar com as formas verbais conjugadas ou formas lexicais, segundo o sentido do texto.

A fim de concluir nossa análise, investigamos a relação texto literário/ensino cultural no corpus. Parece-nos evidente que o texto literário é um dos textos que poderíamos utilizar para ensinar conteúdos culturais. Cuq e Gruca (2005, p.426-427) consideram que

a leitura de um texto literário pode fornecer conteúdos muito diversos segundo os leitores se levamos em conta suas experiências, suas ideologias, sua cultura ou mesmo o contexto particular da leitura. É necessário, portanto, qualquer que seja o público, estabelecer uma conivência cultural a fim de reduzir ao máximo o que comumente designa-se por "choque cultural" e evitar os desnivelamentos interpretativos esperados pelo próprio texto; é possível favorecer o contato com outros e o encontro com o outro através de dados de civilização, de referências às realidades extralinguísticas e extra-textuais que permitem construir uma competência cultural, inteiramente a serviço da comunicação. ${ }^{6}$

De acordo com os autores, a leitura literária é um meio eficaz de aquisição de uma competência cultural, pois ela confronta, a todo instante, a identidade social do aluno e a cultura ensinada. Nessa ótica, a literatura nos parece favorecer que se compartilhem experiências e convidar o leitor a praticar o exercício da alteridade, já que ele é estimulado a descobrir o Outro. Além disso, o fato de adquirir uma competência cultural permitirá ao aluno aperfeiçoar sua competência de compreensão de textos, pois o que torna difícil a leitura, e provoca

${ }^{6}$ La lecture d'un texte littéraire peut fournir des contenus forts divers selon les lecteurs compte tenu de leurs expériences, de leur idéologie, de leur culture, voire même du contexte particulier de la lecture. Il est donc nécessaire, quel que soit le public, d'établir une connivence culturelle, afin de réduire au maximum ce que l'on désigne couramment par "choc culturel » et éviter des dénivellements interprétatifs attendues par le texte même; il est possible de favoriser le contact avec l'ailleurs et la rencontre avec l'autre par données civilisationnelles, par des références aux réalités extra-linguistiques et extra-textuelles qui permettent de construire une compétence culturelle, toute au service d'un enseignement de la communication. 
frequentes mal entendidos, é justamente a falta de elementos socioculturais de referência.

Em relação aos livros que analisamos, poderíamos afirmar que eles sofrem de uma "amnésia cultural"6. De fato, as atividades enfatizam raramente o caráter cultural dos textos literários. Os autores dos livros utilizaram o texto literário para ilustrar a cultura-alvo (festividades, costumes, personalidades, ícones da cultura francesa, etc). Em suma, essa utilização se resume em olhar de fora à cultura ensinada. Os alunos são raramente convidados a entrarem na culturaalvo, a se confrontarem com ela e, sobretudo, a se desfazerem das representações estereotipadas e errôneas que eles possuem a priori.

As atividades propostas no corpus focalizam frequentemente conteúdos culturais associados à vida prática e aos costumes. Percebemos também que o texto literário encarna, de um ponto de vista cultural, a erudição e a importância da cultura escrita. Esses dois olhares sobre a cultura podem ser explicados, de acordo com Cuq e Gruca (2005, p.420) pelo fato de que os livros analisados "perpetuam a infeliz dicotomia cultura/civilização que dividiu em dois, o século passado". No mais, eles teriam uma tendência a reduzir a cultura às produções culturais tangíveis de um grupo (instituições, práticas culinárias, políticos) e à cultura dita "erudita".

\section{Considerações finais}

Em poucas palavras, os livros didáticos fazem uma exploração do texto literário que não é pertinente. De fato, concluímos que as atividades propostas não possuem objetivos pedagógicos apropriados ao texto literário, na qualidade de material de aprendizagem. De maneira geral, as atividades não distinguem o texto literário dos outros gêneros textuais, isto é, essas atividades não consideram as especificidades da literatura.

Outro aspecto que instiga nossa reflexão refere-se à capacidade da literatura de representar um real linguístico. O texto literário poderia ser utilizado para ilustrar uma situação autêntica de comunicação?

\footnotetext{
${ }^{6}$ Termo utilizado por Cuq e Gruca (2005) para designar a falta, nos livros didáticos de FLE, de atividades que levam em conta o aspecto cultural.
} 
Ainda que os textos literários nos forneçam um material linguageiro que nos permita refletir sobre a linguagem - parole no sentido Saussuriano - é importante não perder de vista que se trata igualmente de uma produção artística. Parece-nos apropriado concluir que o fato de apreciar a dimensão artística da literatura tem impactos consideráveis na elaboração de uma sequência pedagógica.

Enfim, esta investigação evidenciou a dificuldade da abordagem comunicativa em adaptar seu aparato teórico aos avanços oriundos de pesquisas no campo do ensino de literatura. Cuq e Gruca (2005, p.419 - 420) indicam o vazio metodológico que existe a respeito do texto literário na concepção de uma metodologia. Os autores destacam um "divórcio" existente entre a pesquisa e a situação da sala de aula. Segundo eles, ao contrário do francês língua segunda e do francês língua materna, o FLE não soube realizar materiais pedagógicos diversificados para o texto literário nem propor estratégias de acordo com as teorias e pesquisas feitas no domínio da didática do texto literário em sala de aula de LE e de literatura. A integração do texto literário em sala de aula FLE continua um desafio que merece ser observado mais atentamente. Esta breve análise evidencia a necessidade urgente de se propor ferramentas didáticas que valorizem esse poderoso "espaço de linguagem" (BARTHES, 1969), a fim de nos apropriarmos do texto literário em sala de aula com mais eficiência.

\section{Referências}

ALMEIDA FILHO, José Carlos P. Dimensões comunicativas no ensino de línguas. Campinas, SP: Pontes, 1993.

BACHMAN, Christian; LINDENFELD Jacky; SIMONIN Jacqueline. Langages et communications sociales. Paris: Hatier, 1981.

BARTHES, Roland. Réflexions sur un manuel: l'enseignement de la littérature. In: DOUBROVSKY, Serge; TODOROV, Tzvetan. (Org.). L'Enseignement de la littérature. Paris: Plon, 1969. p. 170-195. 
BATISTA, Antonio A. G. Um objeto variável e instável: textos impressos e livros didáticos. In: ABREU, Márcia. (Org.). Leitura, história e história da leitura. Campinas: Mercado de Letras, 2000.

BERARD, Eveline. L'approche communicative: théories et pratiques. Paris: Clé International, 1991.

CANALE, Michael., SWAIN, Merrill. Theoretical bases of communicative approach to second language teaching and testing. Applied Linguistics, v. 1, n. 1, p. 28-31 1980.

. From communicative competence to communicative language pedagogy. In: RICHARDS, Jack C.; SCHMIDT, Richard. Language and communication. London: Longman, 1983.

CICUREL Francine. Lectures interactives en langues étrangères. Paris: Hachette, 1991.

CONSELHO DA EUROPA. Quadro europeu comum de referência para as línguas: aprendizagem, ensino, avaliação. Porto: Asa Editores, 2001. Disponível em: <www.asa.pt>. Acesso em: 24 mai 2010.

CORACINI, Maria José R. F. O livro didático nos discursos da Lingüística Aplicada e da sala de aula. In: (Org.). Interpretação, autoria e legitimação do livro didático: língua materna e língua estrangeira. 1 ed. Campinas, SP: Pontes, 1999.

COSTA, Heloisa B. A. Ensino do Francês língua estrangeira e os textos literários nos manuais didáticos. In: SEMINÁRIO DO GRUPO DE ESTUDOS LINGÜÍSTICOS DO ESTADO DE SÃO PAULO, 50., 2002, São Paulo. Anais... São Paulo: GEL, 2002. 1 CD-ROM.

CUQ, Jean Pierre; GRUCA, Isabelle. Cours de didactique du français langue étrangère et seconde. Grenoble: Presses Universitaires de Grenoble, 2005. 
DEMOUGIN, Patrick. Enseigner le français et la littérature: du linguistique à l'anthropologique. Revue de Sciences de l'Education, v. 33, n. 2, p. 401-415, 2007.

ECO, Umberto. Lector in fabula. Paris : Editions Grasset, 1979.

ELENA, Pierre. Du texte littéraire comme intrus performant dans la classe. Le Français dans le Monde: Recherches et Applications, v. 1, n. 1, p. 172-180, juil 2005. Numéro spécial (La didactique au quotidien).

GOLDENSTEIN, Jean-Pierre. Entrées en littérature. Paris: Hachette, 1990.

HYMES, Dell. H. Vers la compétence de communication. Paris: Hatier-Crédif, 1984.

HUTCHINSON, Tom.; TORRES, Eunice. The textbook as agent of change. ELT Journal, v. 48, n. 4, p. 315-328, 1994.

KITAO, Kenji; KITAO, S. Kethleen. Selecting and developing teaching/learning materials. The Internet TESL Journal, v. 4, n. 4, 1997. Disponível em: <http://iteslj.org/Articles/Kitao-Materials.html>. Acesso em: 06 nov 2010.

MOIRAND, Sophie. Enseigner à communiquer en langue étrangère. Paris: Hachette, 1982.

NATUREL, Mireille. Pour la littérature: de l'extrait à l'œuvre. Paris: CLE International, 1995.

PAPO, Eliane; BOURGAIN, Dominique. Littérature et communication en classe de langue. Paris: Hatier, 1989.

PEYTARD, Jean. (Org.). Littérature et classe de langue. Paris: Hatier/Didier, 1982. 
Frank S. Gonçalves e Henrique A. P. Alves

PRABHU, Nagore. S. There is no best method: why? TESOL Quarterly, v. 24, n. 2, p. 161-176, 1990.

RICHARDS, Jack. C; RODGERS, Theodore. S. Enfoques y métodos en la enseñanza de idiomas. 2 ed. Cambridge: Cambridge University Press, 2003.

RIQUOIS, Estelle. Evolutions méthodologiques des manuels et matériels didactiques complémentaires en FLE: de la méthode traditionnelle à la perspective actionnelle. Education \& Formation, v. e-292 p. 129-141, 2010. Disponível em: <http://ute3.umh.ac.be/ revues/index.php?revue=8\&page=3>. Acesso em: 01 out 2010 .

\section{Livros didáticos analisados}

AUGÉ, Hélène et al. Tout va bien. Paris: Clé International, 2004. 4 v.

KANEMAN-POUGATCH, Massia et al. Café crème. Paris: Hachette, 1997. v. 1.

BEACCO DI GIURA, Marcella et al. Café crème. Paris: Hachette, 1997. v. 2.

CAPELLE, Jeanne; CAPELLE, Guy. La France en direct 1. Paris: Hachette, 1969.

DELAISNE, Pierre; MC. BRIDE, Nicole; TREVISI, Sandra. Café crème. Paris: Hachette, 1998. v. 3.

COURTILlON, Janine; RAILLARD, Sabine. Archipel. Paris: Didier, 1982. v. $1,2$.

COURTILlON, Janine; ARGAUD, Marc. Archipel. Paris: Didier, 1987. v. 3.

MAUGER, Gérard. Cours de langue et de civilisation française. Paris: Hachette, 1953. v. 1. 
A presença de textos literários em livros didáticos

MAUGER, Gérard; BRUÉZIÉRE, Maurice. Le français et la vie Paris: Hachette, 1971.

Recebido em: 26/10/2011

Aceito em: $\quad$ 13/02/2012

Titulo: The presence of literary texts in communicative approach oriented textbooks 